p 147). While I welcome the intention of the article in drawing attention to the patchy and faltering implementation of the 1970 Chronically Sick and Disabled Persons Act in many parts of Great Britain, I am astounded at the lack of discussion of the real progress that has been made by OUTSET, among others, in producing and testing efficient methods of identifying the "hidden handicapped" in the community. Your editorial asks, "How can we find the "hidden handicapped ?" and suggests a number of methods, many of which have been looked into and shown to be inadequate. The only method found by us to be reliable is to find out by door-to-door survey where handicapped people are, and follow this up with an in-depth interview of each handicapped person identified in order to ascertain difficulties and requirements.

OUTSET has been involved in over 20 surveys of this nature since the passing of the $1970 \mathrm{Act}$, and more recently has been able to improve techniques substantially by marrying our survey methods to the classification of handicap pioneered by Dr Margaret Agerholm. We have found that our techniques produce a variety of useful information, as well as putting individual handicapped people in touch with relevant services. Currently, we are carrying out, among other projects, a major survey of the whole of Northern Ireland, aiming to obtain a response from each household in the province, and to interview $50000-70000$ handicapped people thus discovered.

I would have thought that the already encouraging success of this venture is in itself a worthy answer to your question. It is with sadness therefore that I observe your reluctance to recommend or indeed mention it.

Alan Whitehead

\section{Craven Street,}

\section{Acute poisoning with Distalgesic}

SIR,-So Dr J A J H Critchley and others (3 February, p 342) wish to start a nationwide campaign on the use and restriction of Distalgesic. Is this not the tail wagging the dog ? At least with the campaign on barbiturates, effective and safer alternatives were available. Distalgesic is widely and correctly used by vast numbers of patients, particularly with rheumatic diseases. I would estimate some $40 \%$ of my patients have taken Distalgesic at some stage: I am unaware of any patient who was unable to give up Distalgesic when the clinical condition had improved and I am unaware of any patient who has become addicted to it. I do not consider that continuing Distalgesic in the medication of an ongoing painful condition is addiction. No patient of mine has yet taken an overdose. Although there may not be adequate double-blind controlled trials proving that Distalgesic is superior to other analgesics, most of the patients who remain on Distalgesic infinitely prefer it to the other analgesic drugs they have tried and that seems a reasonable basis on which to continue prescribing Distalgesic.

Perhaps those who feel strongly about drug abuse (and I have sympathy with their view) should devote their missionary zeal to changing the nature of man or the world, as curbing the use of Diastalgesic will merely transfer drug abuse to another easily available drug, as happened when phenacetin was removed from aspirin, phenacetin, and codeine tablets.
The incidence of suicide has not greatly changed since coal gas was withdrawn: people merely use different agents. On epidemiological grounds I wonder whether Dr Critchley et al are correct. Distalgesic is very widely prescribed and the admission of 130 cases of self-poisoning in a year may only reflect the frequency with which Distalgesic is prescribed, rather than suggesting that it is the most popular drug for drug abuse.

It is remarkable how just a little abuse by a few can affect thousands of satisfied users-as in the case of the paternoster lift at Northwick Park, which has been out of use for six months as a result of being abused by a skylarking juvenile (delinquent) unconnected with the hospital. Many have suffered gross inconvenience meanwhile.

J M GUMPEL

Northwick Park Hospital and Clinica Research Centre

\section{Storage and cooking of poultry}

SIR,-Readers who consulted your leading article (18 November, $p$ 1385) on the storage and cooking of poultry will have had a Merry Christmas and escaped a food-poisoning infection. In order to do so, however, they must have risen inordinately early on Christmas Day. Your advice to cook a large turkey of, say, $20 \mathrm{lb}$ weight for 30 minutes per $\mathrm{lb}$ at $200^{\circ} \mathrm{C}\left(400^{\circ} \mathrm{F}\right)$ in a preheated oven implies a cooking time of 10 hours. At this temperature the bird would be well cookedsome might claim too well cooked, but at least it would be safe.

Those who do not read your journal or were too lazy to get up early on Christmas morn could follow the advice of the British Turkey Federation, circulated by the DHSS in $\mathrm{HN}(77) 190$, and lie in bed with a clear conscience. Their bird of the same weight required only $10 \frac{1}{2}$ minutes per $\mathrm{lb}$ at $177^{\circ} \mathrm{C}$ $\left(350^{\circ} \mathrm{F}\right)$-a total cooking time of only $3 \frac{1}{2}$ hours and at $23^{\circ} \mathrm{C}$ lower temperature.

Those of us who are asked to give advice find it difficult to reconcile these two statements. Infections due to salmonella and Clostridium perfringens continue to be associated with the eating of turkeys. We need evidence to support one or other of these authorities. Is such evidence available?

A E WRIGHT Public Health Laboratory, Gloucester A WITHNEL Area Medical Officer, Gloucester

\section{How to use a library}

SIR,-Medical librarians are nearly always pleased at any attempt to publicise the collections in their care, or the services they try to offer; and most of us these days can do with al the help we can get-but some of us will have read Dr M G Timbury's article (27 January, p 252) with some disappointment. Although realise that this presented the views of one departmental librarian, and that it did contain some useful information, the role of the medical librarian was dealt with in four lines.

The task of carrying out detailed searches of an ever-expanding literature, with all its complexities, is one many of us would regard as something only trained, skilled, and experienced librarians can do. This is not to say that readers cannot often help themselves; but medical librarians are in a special position because, unlike doctors, they are able to concentrate on the literature "for itself alone" and are not directly concerned with its implementation-in other words, they are able to act as a bridge between the literature and the reader.

Librarians are used to being a somewhat misunderstood profession and are accustomed, on the one hand, to having effusive praise for merely telling a reader where the $B M f$ is located and, on the other hand, to meeting a lack of understanding of the many techniques and often considerable experience involved in dealing with highly complex bibliographical inquiries. Nevertheless, some readers in the past have recognised the role we play; and in 1953 Sir Cecil Wakeley, the president of the First International Congress on Medical Librarianship, reminded us that "some of the finest consultants available are to be found in medical libraries"-meaning medical librarians. Many of us would be quite content to accept this evaluation of our work.

In recent years some valuable papers by medical librarians have appeared, and one could cite the excellent series by Miss F M Picken..$^{12}$ I do not wish to comment on $\mathrm{Dr}$ Timbury's recommendations or the references she gives in further detail but I was surprised that, although she cited Mr L T Morton's Use of Medical Literature, 2nd edition, 1977, she did not refer to the other book by one of our most distinguished medical librariansHow to Use a Medical Library, ${ }^{3}$ which first appeared in 1934.

The Library,

Cardiothoracic Institute,

London SW3

1 Picken, F M, Teach-In, 1974, 3, 302, 237, 297, 427, and 506 .

Picken, F M, Hospital Update, 1975, 1, 59 and 563. Morton, $\mathrm{L}$, How to Use a Medical Library, 6th edn.
London, Heinemann, in press.

SIR,-I read with interest the excellent article by Dr Morag Timbury on "How to use a library" (27 January, p 252). As she points out, she has presented her own viewpoint, but has nevertheless covered sufficient points to provide an adequate introduction to library use.

Might I, however, elaborate on just a few of her points? Index Medicus is all Dr Timbury says it is-but it is also something more. For the last few years it has included a selection of monographs-mostly conference proceedings and the like, listing the individual papers by author and subject. For those who may wish to know whether a particular conference has reached publication, there is a useful publication called Directory of Published Proceedings: Series SEMT"' (science, engineering, medicine, and technology). The National Library of Medicine Current Catalog is indeed a useful bibliography. I have found that its greatest asset is its listing of US Government publications.

With regard to Medline, Dr Timbury suggests that most main libraries have direct access to the computer. There are many which do not. But even the smallest medical libraries usually have access to the postal service of Medlars, which, although somewhat slower, is preferable on occasion to manual searching. Perhaps it should be mentioned that computer searches are an expensive pastime and should be reserved for the more complicated searches. 